

Revista Nacional de

Gerenciamento de Cidades

\title{
HABITAÇÕES COLETIVAS PRECÁRIAS DE ALUGUEL NO BAIRRO VARADOURO (JOÃO PESSOA/PB) E SUAS CONDIÇÕES DE HABITABILIDADE
}

\author{
Camila Coelho Silva ${ }^{1}$
}

\author{
Jovanka Baracuhy Cavalcanti Scocuglia ${ }^{2}$
}

\begin{abstract}
RESUMO
Além da função de abrigo e proteção contra as intempéries, a moradia tem o papel de oferecer condições para garantia da saúde e do bem-estar físico-mental dos indivíduos que a utilizam, realidade contrária à da habitação popular brasileira. Moradores de habitações coletivas de aluguel (vilas, cortiços, etc.) e de outras formas ilegais/informais de moradia no Brasil têm enfrentado um quadro de grande precariedade, residindo em casas cujas dimensões e condições físicas comprometem a vida e a saúde familiar. Este artigo apresenta parte dos resultados de pesquisa recente para elaboração de dissertação de mestrado junto ao PPGAU-UFPB e objetiva analisar as condições de habitabilidade das habitações coletivas precárias de aluguel (HCPAs) (re)produzidas no centro da cidade de João Pessoa-PB. Para cumprimento de tal objetivo, estas formas de moradia foram identificadas, mapeadas e analisadas a partir da criação de uma ficha de levantamento com foco nas condições de habitabilidade urbana e habitacional. A pesquisa empírica permite perceber que, apesar do quadro de inconformidade das habitações aos ideais do morar adequado/saudável, das dificuldades enfrentadas devido à condição de coletividade e invisibilidade, da ausência da ação qualificada do Estado, bem como das incertezas que o mercado informal oferece, os cortiços e vilas populares resistem e seus moradores (sobre)vivem sem esperanças de melhorias nas habitações, mas, ainda assim, preservam a vida da área central da cidade.
\end{abstract}

PALAVRAS-CHAVE: Habitações coletivas precárias de aluguel. Habitabilidade. Área Central.

\footnotetext{
${ }^{1}$ Arquiteta e Urbanista mestranda em Arquitetura e Urbanismo, Universidade Federal da Paraíba UFPB. camilacoelhos@hotmail.com

${ }^{2}$ Arquiteta e Urbanista com pós-doutorado em Sociologia Urbana e Antropologia, docente e pesquisadora do Departamento de Arquitetura da Universidade Federal da Paraíba - UFPB. jovankabcs@gmail.com
} 




Revista Nacional de

Gerenciamento de Cidades

\title{
HOUSING COLLECTIVE PRECARIOUS RENTAL IN NEIGHBORHOOD VARADOURO (JOÃO PESSOA/PB) AND CONDITIONS HABITABILITY
}

\begin{abstract}
In addition to the function of shelter and protection from the inclement weather, the housing has the role of providing conditions to ensure the health and the physical-mental welfare of individuals who use, opposite reality to the Brazilian popular housing. Residents of multifamily housing of rent (vilas, cortiços, etc.) and other illegal/informal forms of housing in Brazil have faced a great precariousness frame, residing in houses whose dimensions and physical conditions compromise the life and family health. This article presents some recent research results for elaboration of master dissertation by the PPGAU-UFPB and aim at analyze the habitability conditions of substandard multifamily housing of rent (HCPAs) (re) produced in downtown of the city of João Pessoa-PB. To fulfillment of this goal, these forms of housing were identified, mapped and analyzed from creating a survey form focused on the conditions of urban and housing habitability. The empirical research allows realize that, despite the disagreement frame of housing as opposed to the ideals of suitable/healthy living, the difficulties faced due to the condition of collectivity and invisibility, the lack of qualified state action, as well as the uncertainties that the informal housing market offers, the cortiços and vilas resist and its residents (over)living in dwellings with no hope of improvement, but still preserve the life of the downtown of the city.
\end{abstract}

KEYWORDS: Substandard multifamily housing of rent. Habitability. Central area.

\section{VIVIENDA DE ALQUILER PRECARIA COLECTIVA EN BARRIO VARADOURO (JOÃO PESSOA/PB) Y LAS CONDICIONES DE HABITABILIDADE}

\begin{abstract}
RESUMEN
Además de la función de refugio y protección contra las inclemências del tempo, la casa tiene la función de proporcionar las condiciones para garantizar la salud y el bienestar físico y mental de las personas que la utiliza, realidad contraria a la vivienda popular brasileña. Los residentes de viviendas colectivas de alquiler (villas, conventillos, etc.) y otras formas ilegales/informales de viviendas en Brasil se han enfrentado a un gran marco de precariedad, viviendo en casas cuyas dimensiones y las condiciones físicas ponem en peligro la vida y salud familiar. Este artículo presenta algunos resultados de investigaciones recientes para elaboración de disertación de master por lo PPGAUUFPB y objetiva analizar las condiciones de habitabilidad de las viviendas colectivas precarias de alquiler (HCPAs) (re) producidas en el centro de la ciudad de João Pessoa-PB. Para cumplir con este objetivo, estas formas de vivienda fueron identificadas, mapeadas y analizadas desde la creación de un formulario de levantamiento centrado en las condiciones de habitabilidad urbana y habitacional. La investigación empírica nos permite entender que, a pesar del marco de desacuerdo de la vivienda en comparación con los ideales do vivir apropiado/sano, de las dificultades que enfrentan debido a la condición de colectividad y la invisibilidad, la falta de acción cualificada del Estado, así como las
\end{abstract}


Revista Nacional de

Gerenciamento de Cidades

incertidumbres que el mercado informal ofrece, los conventillos y villas populares resisten y sus residentes (sobre)viven en las viviendas sin esperanza de mejora, pero aún conservan la vida de la área central de la ciudad.

PALABRAS-CLAVE: Viviendas colectivas precarias de alquiler. Habitabilidad. Área Central.

\section{INTRODUÇÃO}

O problema habitacional e o processo de deterioração crescente dos centros urbanos, em especial dos chamados "centros históricos" ${ }^{3}$, vem sendo abordado nas últimas décadas por importantes estudos (SANTOS, 1986; VILLAÇA, 2001; CANDIDO; PEREIRA, 2005; KOWARICK, 2007; ROLNIK; BOTLER, 2004; SCOCUGLIA, 2004, 2010; DAVIS, 2006; entre outros). Este processo, justificado, sobretudo, pelo fator econômico no que diz respeito à dinâmica de crescimento urbano, reflete diretamente na desvalorização e esvaziamento de imóveis, bem com na degradação dos espaços públicos, embora, paradoxalmente, sejam áreas contempladas com infraestrutura urbana básica e com transporte público subutilizados nesse contexto.

O revés deste processo é a atração de uma nova população moradora empobrecida e novas formas de ocupação desses espaços. Um de seus principais fenômenos resultantes e questão expressiva desde o século XIX é a multiplicação de habitações coletivas precárias de aluguel (HCPAs) na forma de vilas e cortiços, características do processo de urbanização dos centros das cidades brasileiras, marcado pelas péssimas condições habitacionais, pelo encarecimento do

\footnotetext{
${ }^{3}$ Conhecido por diversas denominações, como centro tradicional, centro histórico, centro principal, etc., esta região sempre foi conhecida, segundo Maia (2009, p.181), como "a área mais dinâmica da cidade, movida pelo fluxo de pessoas, de veículos e de mercadorias, decorrente da marcante presença do comércio, dos serviços varejistas, das instituições financeiras, administrativas, de ensino, de saúde e também religiosas". O centro é também local de encontro, de moradia e de trocas sociais. Ainda segundo a autora, esta concentração de atividades em certo espaço fomentou no que se denomina de centralidade intra-urbana.
} 




Revista Nacional de

Gerenciamento de Cidades

preço da moradia, pela segregação socioespacial, e, nas palavras de Corrêa (2013), pela segregação residencial ${ }^{4}$.

Impossibilitados de possuírem casa própria, ou de alugarem moradias melhores devido aos altos valores de aluguéis, ou ainda pela necessidade de residirem próximos ao local de trabalho pelo custo da mobilidade urbana, e evitando residir em favelas, os indivíduos de baixa renda não tem outra opção senão o aluguel de habitações coletivas, geralmente precárias, insalubres e sem o mínimo de condições necessárias à habitabilidade. Corrêa (1995), ao retratar a sociedade com base na divisão de classes, afirma que "a habitação é um desses bens cujo acesso é seletivo: parcela enorme da população não tem acesso, quer dizer, não possui renda para pagar o aluguel de uma habitação decente e, muito menos, comprar um imóvel" (CORRÊA, 1995, p.29).

Sabe-se que, além da função de abrigo e proteção contra as intempéries, a moradia tem o papel de oferecer condições para a garantia da saúde e do bem-estar físico-mental dos indivíduos que a utilizam. Nas palavras de Carvalho (2008, p.21), "a moradia urbana contemporânea é um complexo conjunto de ideias que envolvem proteção, conforto, saúde, privacidade, domesticidade, segurança, economia, entre outros, e estas complementam o todo trazendo qualidade e singularidade à habitação".

Embora sejamos cientes deste direito, a realidade da habitação popular brasileira segue na direção contrária, não ofertando qualidade nem mesmo para as

\footnotetext{
${ }^{4}$ A segregação exerce um importante papel na análise e diagnóstico do espaço urbano de nossas cidades, uma vez que, Segundo Villaça (2011, p.37), é "a mais importante manifestação espacialurbana da desigualdade que impera em nossa sociedade. (...) nenhum aspecto do espaço urbano brasileiro poderá ser jamais explicado/compreendido se não forem consideradas as especificidades da segregação social e econômica que caracteriza nossas metrópoles, cidades grandes e médias". O autor define o fenômeno como um processo segundo o qual "diferentes classes ou camadas sociais tendem a se concentrar cada vez mais em diferentes regiões gerais ou conjuntos de bairros da metrópole" (VILLAÇA, 2001, p.142). Tal fenômeno torna ainda mais complexo os processos de estruturação do espaço urbano, promovendo, dentre outros fatores, uma cidade dispersa e uma urbanização difusa, o surgimento de novas centralidades e a degradação dos centros antigos, e o aumento das desigualdades socioespaciais. Já Corrêa (2013) traz o termo "segregação residencial" que diz respeito "à concentração no espaço urbano de classes sociais, gerando áreas sociais com tendência à homogeneidade interna e à heterogeneidade entre elas" (CORREA, 2013, p.40).
} 




Revista Nacional de

Gerenciamento de Cidades

necessidades básicas supracitadas. É este o quadro de precariedade que moradores de habitações coletivas de aluguel, favelas, loteamentos clandestinos e demais assentamentos subnormais têm enfrentado no Brasil, residindo em casas deterioradas, abandonadas, ou em barracos, cujas dimensões e condições físicas comprometem a vida e a saúde familiar.

Evidencia-se o aumento do número de domicílios irregulares caracterizados pela densidade construtiva e populacional através da subdivisão de unidades habitacionais, da construção de acréscimos nas edificações ou ainda mediante sua verticalização, além da carência de infraestrutura. Estes fatores refletem-se diretamente nas condições de habitabilidade, como Norma Lacerda explica: "Evidentemente, o vertiginoso processo de adensamento construtivo tem implicações nos indicadores de habitabilidade (cômodos sem aeração, sem exposição ao sol...)" (LACERDA, 2011, p.19).

É neste contexto que as habitações coletivas de aluguel ${ }^{5}$ da área central da cidade de João Pessoa se inserem. Embora seja uma área já dotada de infraestrutura urbana devido à condição de compor o núcleo de origem da cidade, a forma como estas habitações são reproduzidas geram inúmeros problemas para a qualidade habitacional, relacionados às precárias condições das instalações elétricas e hidráulicas, à ausência ou pouca iluminação e ventilação naturais, ao uso coletivo de áreas molhadas, à umidade, às pequenas áreas dos cômodos, à falta de privacidade, à insegurança da posse da terra, à coletivização de WCs, dentre outros aspectos.

\footnotetext{
${ }^{5}$ O termo habitações coletivas precárias de aluguel ou HCPAs, utilizado por Piccini (2004) e adaptado nessa pesquisa, refere-se à unidade usada como moradia multifamiliar e acessada através da locação ou sublocação, apresentando, total ou parcialmente, as seguintes características: a) Ser constituída por uma ou mais edificações construídas em lote urbano; b) Ser subdividida em mais de uma unidade habitacional; c) Utilizar o mesmo ambiente para exercer diversas funções (estudar, dormir, cozinhar, fazer refeições, trabalhar, etc.); d) Ter acesso comum dos espaços não edificados; e) Apresentar uso comum das instalações hidráulicas e sanitárias, como banheiros, cozinhas e/ou tanques; f) Oferecer infraestrutura, no geral, precária, causando riscos para saúde ou de vida (ventilação e iluminação naturais inadequadas, umidade excessiva, infiltrações, instalações elétricas e hidráulicas em más condições, etc.); g) Apresentar superlotação de pessoas.
} 
Revista Nacional de

Gerenciamento de Cidades

Apesar de haver uma gama significativa de estudos sobre revitalização, requalificação ou reabilitação de centros históricos em processo de deterioração, as habitações precárias a que nos referimos aqui parecem ausentes ou pouco exploradas na literatura sobre a política habitacional recente nas cidades brasileiras, em especial no centro primaz da cidade de João Pessoa. Há, assim, certa "invisibilidade" do fenômeno nas pesquisas, nas estatísticas oficiais e até mesmo física perante os olhos dos transeuntes, se configurando como uma das maneiras pelas quais essa forma de moradia e de comercialização do espaço urbano se reproduz e se mantém, ocultando uma triste realidade de precárias condições de moradia e de vida de inúmeros indivíduos.

Tendo em vista fatores como o baixo investimento, o lucro garantido, a desconsideração das leis urbanísticas e habitacionais por parte dos locadores, os limitados recursos financeiros, a necessidade de residir próximo ao trabalho e a impossibilidade de se morar em uma habitação digna por parte dos locatários, percebe-se a importância do estudo das condições de habitabilidade das habitações coletivas de aluguel identificadas no centro antigo da cidade de João Pessoa.

Neste sentido, este artigo apresenta parte das reflexões teóricas desenvolvidas para a elaboração de uma dissertação de mestrado junto ao Programa de Pós Graduação em Arquitetura e Urbanismo - PPGAU-UFPB, e tem como objetivo avaliar as condições de habitabilidade urbana e habitacional das habitações coletivas de aluguel inseridas no centro antigo da cidade de João Pessoa, mais precisamente no bairro do Varadouro, onde se desenvolveu um misto de atividades de comércio, serviços e habitação desde os primórdios da constituição e crescimento da cidade.

Para tanto, o artigo se estrutura da seguinte forma: inicialmente, trazemos a discussão sobre os conceitos de habitabilidade urbana e habitacional, explanação essencial para compreensão e desenvolvimento do estudo; em seguida, apresentamos o recorte de estudo, o bairro do Varadouro, João Pessoa-PB, justificando sua escolha; na sequência, tratamos da metodologia e dos 
procedimentos de pesquisa aplicados; o próximo tópico ilustra a precariedade das condições de habitabilidade identificadas na pesquisa empírica de 2012/2013, que incentivou a continuação da investigação; por fim, tecemos breves considerações, tendo em vista que a pesquisa ainda se encontra em curso.

\section{A HABITABILIDADE URBANA E DA UNIDADE HABITACIONAL E A MORADIA POPULAR}

$\mathrm{Na}$ discussão sobre o habitar saudável, diversos países fazem uso da regulamentação da construção com o intuito de evitar danos à saúde dos moradores, bem como a baixa qualidade construtiva e sanitária. De acordo com Carvalho (2008), a legislação edilícia e normas brasileiras definem que, para ser considerado minimamente adequado, um domicílio deve possuir banheiro, cozinha e pelo menos um cômodo habitável, além de apresentar condições satisfatórias de higiene, segurança e habitabilidade. Embora estes três fatores sejam citados, não existem definições específicas sobre eles, fato que exprime a incerteza nos critérios para se alcançar uma moradia minimamente apropriada.

Segundo Blachere (1978, apud ANJOS; BARBOSA, 2014), a habitabilidade diz respeito ao conjunto de carências do homem como ser vivo, inteligente e social. Nesse sentido, consideram-se as necessidades fisiológicas, psicológicas e sociológicas correspondentes ao edifício e, em especial, à habitação.

Outros autores, como Malard (1992), Szucs (2000), Almeida (2001) (apud CHIARELLI, 2006, p.27) e, mais recentemente, Elisangela Silva (2011), acreditam que o habitar é uma característica essencial da vida do homem e, por conseguinte, a relação entre o espaço construído e o usuário deveria ser uma experiência plena. Assim, defendem que a habitabilidade envolve questões pragmáticas, simbólicas e funcionais.

A dimensão pragmática relaciona-se à capacidade do domicílio atender como abrigo, abarcando as variáveis de desempenho construtivo da moradia e a sua inserção urbana. A dimensão simbólica refere-se à capacidade da casa de ser 
Revista Nacional de

Gerenciamento de Cidades

dotada de significado, ou seja, considera as questões culturais. Por fim, a dimensão funcional diz respeito à capacidade da casa de proporcionar boas condições ao uso dos espaços, relacionada ao dimensionamento da moradia, relação funcional entre os cômodos e manutenção (SILVA, 2011).

Como visto, para a compreensão das condições de habitabilidade, múltiplos fatores de ordem físico-espacial, social, econômica e cultural podem ser avaliados, considerando desde a escala da unidade habitacional até a conjuntura urbana em que a habitação está inserida. Destarte, os conceitos de Habitabilidade Urbana e da Unidade habitacional vigoram a questão do espaço arquitetônico como a totalidade da fruição, usufruição e construção da habitação adequada, saudável.

Conforme descreve Cohen (2004, p.27; 2007, p.194), o conceito Habitabilidade Urbana defende que a habitação precisa e deve ser compreendida em um sentido mais abrangente e sistêmico, na acepção de pertencimento, de usufruto e de direito à cidade. Ou seja, abrange a oferta e o acesso da população à rede de infraestrutura urbana, além do acesso aos equipamentos públicos.

Assim, para analisarmos as condições de habitabilidade urbana, consideramos os requisitos mínimos de qualquer assentamento urbano, como existência ou não de iluminação elétrica e a forma como ela é fornecida, o abastecimento de água, o esgotamento sanitário e a coleta de lixo, assim como a existência e a proximidade dos equipamentos urbanos básicos como postos de saúde, escolas, farmácias, mercados, etc. Todos esses fatores interferem diretamente na qualidade de vida dos moradores e se fazem presentes de forma representativa nos centros urbanos brasileiros.

Conceito bastante estudado e debatido na contemporaneidade, a Habitabilidade da Unidade Habitacional trata do conjunto de aspectos que interviriam na qualidade de vida e na comodidade dos moradores, assim como na satisfação de suas necessidades físicas, psicológicas e socioculturais. A partir dele, podemos avaliar questões como conforto ambiental (luminoso, térmico, acústico e táctil), segurança do usuário, salubridade domiciliar e do seu entorno. Bonduki explica: 




\section{Revista Nacional de}

Gerenciamento de Cidades

O Varadouro é indicado pela literatura da história da cidade de João Pessoa e por historiadores como sendo um dos bairros mais antigos onde se desenvolveu um misto de atividades de comércio, serviços e habitação e onde se estabeleceram algumas das ruas comerciais mais dinâmicas durante muitos anos como, por exemplo, as Ruas da República, Maciel Pinheiro, Beaurepaire-Rohan e Barão do Triunfo.

Figura 01: Localização do bairro Varadouro na cidade de João Pessoa-PB.



Fonte: Mapa Urbano Digital de João Pessoa - Diretoria de Geoprocessamento e Cadastro Urbano DIGEOC-SEPLAN - PMJP, editado por Camila Coelho, 2014.

Após os anos 1950, deu-se início ao processo de abandono da área pelos moradores mais abastados e, em seguida, pelos comerciantes, apresentando-se, com o decorrer dos anos, como um bairro marcado pela prostituição, marginalidade e por ser local de moradia de uma população estigmatizada, residente em ocupações irregulares, como as comunidades Porto do Capim e Maurício de Nassau, às margens do Rio Paraíba. 
Revista Nacional de

Gerenciamento de Cidades

Segundo dados do IBGE, o processo de esvaziamento populacional continua. No Censo de 2010, foram identificados 3.720 residentes, enquanto que no Censo de 2000 havia 4.098. Percebe-se, assim, uma redução de 378 moradores entre os anos 2000 e 2010. A queda constante do número de residentes não apenas no bairro do Varadouro, mas na área central de João Pessoa como um todo, tem deixado marcas de degradação, deterioração e descaracterização da arquitetura representativa da região, bem como dos espaços públicos e, consequentemente, da paisagem citadina.

Levou-se ainda em consideração não só a precariedade de suas habitações coletivas de aluguel, mas a degradação pelo qual o bairro vem passando nos últimos anos, apesar dos projetos de requalificação de suas praças e do Convênio BrasilEspanha de Cooperação Internacional, que promoveram a preservação de alguns dos seus imóveis tombados pelos órgãos oficiais de patrimônio e buscaram sua reinvenção com a constituição de um cenário de consumo e lazer (SCOCUGLIA, 2004).

Por fim, o Varadouro é o bairro do centro histórico da cidade onde o poder público vem tentando implantar políticas de incentivo à habitação social para minimizar problemas como a carência de moradias e o aumento das habitações em áreas de risco da população de baixa renda, através de projetos como a Vila Moradouro $^{6}$, que reforçam a importância da área para a habitação.

\section{PROCEDIMENTOS METODOLÓGICOS}

Para avaliar as condições de habitabilidade das habitações coletivas precárias de aluguel, partindo da pesquisa bibliográfica e da construção do

\footnotetext{
${ }^{6}$ Um projeto marcante na tentativa de reinserção do uso habitacional na área central da cidade de João Pessoa, mais precisamente no bairro do Varadouro, foi o Projeto Moradouro, tendo como objetivo "a reabilitação do estoque imobiliário presente no centro histórico e que se encontra em estado precário de conservação. Através desta intervenção se espera atrair novos moradores para a área (...)" (CAVALCANTE, 2009, p.138). Instituído na gestão de Cícero Lucena (2002), relançado pela gestão de Ricardo Coutinho (2007), e reintroduzido na discussão sobre o morar na área central no ano passado (2014) na gestão de Luciano Cartaxo, o programa teve poucas intervenções executadas, devido a inúmeros impasses encontrados.
} 




Revista Nacional de

Gerenciamento de Cidades

referencial teórico-conceitual, estabelecemos um modelo de ficha de levantamento, bem como roteiros de formulários/entrevistas para locadores e locatários. Apresentamos nesta seção como se estruturou a ficha que reúne os dados necessários para análise da habitabilidade das HCPAs identificadas na pesquisa empírica.

Com o objetivo de identificar, caracterizar e avaliar as condições de habitabilidade urbana e habitacional das HCPAs, a ficha foi divida em quatro partes. A primeira parte contempla a identificação geral da HCPA através do endereço, mapa de localização e registro fotográfico da fachada do imóvel. O segundo tópico trata da habitabilidade urbana, tomando como base a discussão teórica relatada anteriormente, e considera a existência e o tipo de fornecimento de infraestrutura urbana e serviços públicos, como destino do lixo, energia elétrica, abastecimento de água e esgotamento sanitário.

A terceira parte concentra as variáveis de desempenho construtivo. São considerados o número de pavimentos, localização no lote, estado de conservação das fachadas ${ }^{7}$, material das paredes e da coberta, número de unidades habitacionais, presença de instalações hidráulicas coletivas, quantidades de banheiros na HCPA, número aproximado de moradores, menor/maior número de moradores por unidade habitacional e registros fotográficos da moradia coletiva.

Por fim, o quarto tópico reúne dados para avaliação da habitabilidade da unidade habitacional, bem como do mercado imobiliário informal de locação, através da coleta dos seguintes elementos: área da unidade habitacional, estado de conservação da estrutura interna, valor do aluguel e se este inclui despesas de água e/ou energia, valor do $\mathrm{m}^{2}$, divisão dos cômodos e sobreposição de funções.

Ainda neste último tópico, é proposta a avaliação das condições de conforto ambiental da unidade habitacional a partir dos seguintes fatores: iluminação natural, ventilação natural, instalações elétricas, instalações hidráulicas, isolamentos de

\footnotetext{
${ }^{7}$ O estado de conservação das fachadas, bem como da estrutura interna, é analisado a partir do ponto de vista da pesquisadora, comparando com as habitações identificadas, sendo caracterizado como bom, regular ou deteriorado.
} 




Revista Nacional de

Gerenciamento de Cidades

ruídos externos à habitação e isolamento de ruídos entre cômodos. Como a pesquisa não propõe a mensuração de fatores e sim a análise a partir dos sentidos dos usuários e técnicos, a avaliação das condições de conforto ambiental no tocante à iluminação, acústica e térmica é feita pelo consenso entre a satisfação dos usuários e a avaliação técnica (avaliação da pesquisadora através da observação in loco), utilizando-se uma escala de três pontos com as alternativas bom-regularruim $^{8}$. Encerra-se o quarto tópico com a exposição de fotos que registrem todos os elementos analisados no tópico referente à unidade habitacional.

Em cada HCPA, visitamos duas unidades habitacionais em diferentes horários do dia (sendo necessário por vezes repetir as visitas em dias diversos) e entrevistamos seus inquilinos, permitindo a comparação das condições de habitabilidade habitacional de cada uma delas. O levantamento foi concluído e todas as fichas foram preenchidas, desenvolvendo-se em seguida a fase de triangulação e análise dos dados coletados na pesquisa empírica.

\section{AS HCPAS NO BAIRRO DO VARADOURO E SUAS CONDIÇÕES DE HABITABILIDADE}

Cientes da condição de degradação e esvaziamento da área central da cidade de João Pessoa, atentamos para a existência das habitações coletivas na área central no ano de 2012, ao percorrermos as ruas do bairro e observarmos com maior atenção a movimentação intensa de certas residências, bem como a presença constante de becos e entradas laterais em algumas de suas habitações. A partir disso, nos propusemos a identificar e analisar as vilas e cortiços do bairro Varadouro no trabalho final de graduação do curso de Arquitetura e Urbanismo desenvolvido no segundo semestre de 2012 e início de 2013. Trazemos aqui informações sobre as HCPAs identificadas no primeiro levantamento, expondo suas péssimas condições de habitabilidade.

\footnotetext{
${ }^{8} \mathrm{~A}$ escala foi escolhida devido à relativa facilidade de compreensão dos termos, além da razoável possibilidade de se graduar os conceitos. Ela direciona o entrevistado a optar por uma resposta desfavorável (ruim), intermediária (regular) ou favorável (bom).
} 




\section{Revista Nacional de}

Gerenciamento de Cidades

$\mathrm{Na}$ pesquisa de campo de 2012/2013 foram encontrados, no total, 45 cortiços e vilas no bairro do Varadouro (figura 02 ), dos quais $80 \%$ permitiram nossa visita. Além da representativa presença de habitações coletivas nessa área, pudemos identificar como o estoque construído da região apresenta-se subutilizado, e, apesar de sua densidade, é expressivo o número de imóveis abandonados e terrenos vazios.

Figura 02: Levantamento de Vilas e Cortiços do Varadouro realizado em 2012/2013.



2013.

No que diz respeito à estrutura das habitações coletivas $^{9}$, apenas quatro imóveis apresentam boa conservação, 14 exibem conservação regular e a maioria, 17 imóveis, tem sua estrutura externa em más condições (figuras 03, 04 e 05).

Figuras 03, 04 e 05: Imóveis representando os níveis de conservação da estrutura externa: bom $[A]$, regular $[B]$ e deteriorado $[C]$.

\footnotetext{
${ }^{9}$ A classificação foi realizada a partir do que foi constatado visualmente nas visitas com relação à qualidade de revestimentos de parede e piso interna e externamente à edificação, à presença/ausência de rachaduras ou outras patologias na estrutura dos imóveis, às condições físicas de elementos como portas, janelas, estrutura de coberta e acessos às unidades habitacionais, entre outros fatores.
} 




\section{Revista Nacional de}

Gerenciamento de Cidades
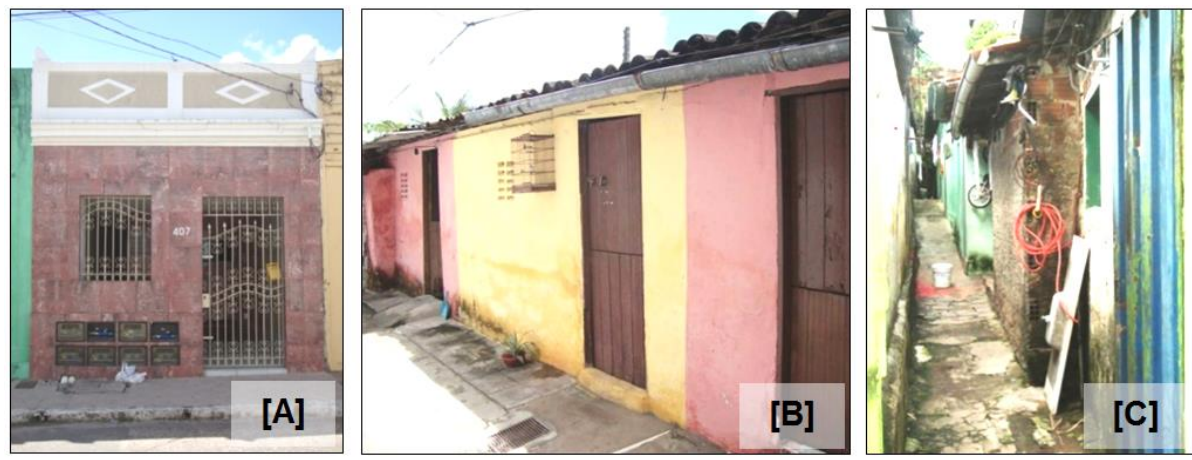

Fonte: SILVA, C., 2013.

Com relação à presença de iluminação e ventilação naturais ${ }^{10}$, constatamos que na grande maioria das unidades de moradia, 29 das 36 unidades visitadas $(80,6 \%)$, aquelas se fazem presentes de forma precária, o que corrobora as péssimas condições de habitabilidade destes imóveis e traz como consequência diversas doenças para seus inquilinos (figuras 06, 07 e 08). Tais doenças, principalmente relacionadas a problemas respiratórios como rinite alérgica e asma, são provavelmente ocasionadas pela presença de mofos, fungos e ácaros que se proliferam abundantemente em ambientes fechados e úmidos. Foram identificados ainda sete imóveis com situação adequada $(19,4 \%)$, números muito baixos quando nos referimos à quantidade de residências coletivas identificadas.

\footnotetext{
${ }^{10}$ As habitações coletivas classificadas como em condições adequadas são aquelas que apresentam condições mínimas de habitabilidade, com boa quantidade de aberturas para o exterior, apresentando assim iluminação e ventilação naturais distribuídas em seus ambientes, e com sistema elétrico e hidráulico em apropriadas condições físicas e de instalação. Já os imóveis indicados como em condições precárias não respeitam esses fatores, oferecendo cômodos mal ventilados e iluminados devido à ausência de aberturas para o exterior da edificação, bem como esgotamento sanitário a céu aberto e fiações e canos antigos e expostos, proporcionando riscos à vida e à saúde de seus inquilinos.
} 




\section{Revista Nacional de}

Gerenciamento de Cidades

Figuras 06, 07 e 08: Habitações coletivas que exemplificam a precariedade da presença de iluminação e ventilação naturais dentre os imóveis estudados.


Em se tratando das instalações elétricas e hidráulicas, novamente temos elevados números quanto à sua precariedade, embora cresça o número de instalações em condições adequadas. Dentre os 36 cortiços e vilas visitados, 22 apresentam suas instalações de forma precária $(61,1 \%)$ e 14 de forma adequada $(38,9 \%)$ (ver figuras 09 e 10$)$.

Figuras 09 e 10: Imóveis ilustrando a precariedade das instalações elétricas e hidráulicas encontrada em grande parte das edificações visitadas.


Fonte: SILVA, C., 2013.

Quanto ao número de banheiros, constatamos que em 30 imóveis $(83,3 \%$ das habitações visitadas) há um banheiro para cada unidade habitacional. Foram identificados, ainda, três imóveis que oferecem dois banheiros em algumas de suas 


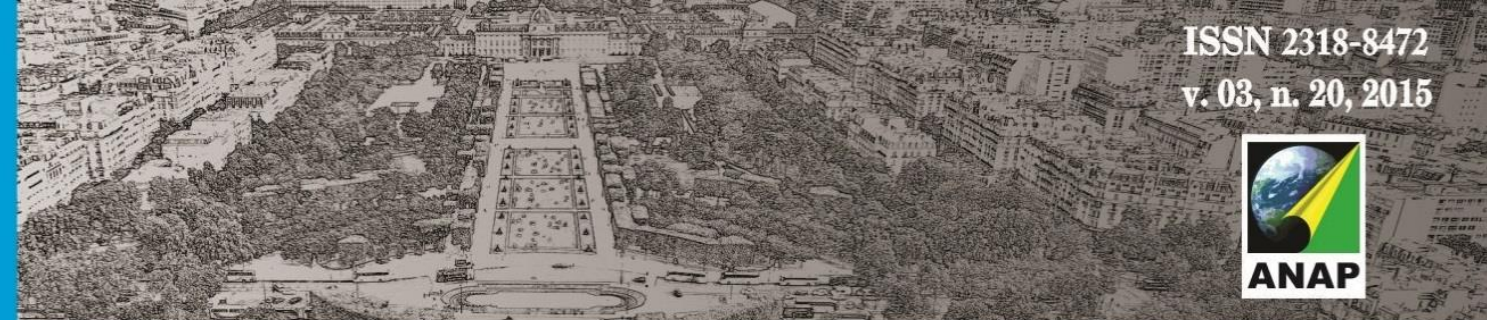

\section{Revista Nacional de}

Gerenciamento de Cidades

Figuras 14, 15 e 16: Casos de sobreposição de funções.


Fonte: SILVA, C., 2013.

Quanto ao número de unidades habitacionais que as vilas e cortiços concentravam, foram identificados 13 imóveis com uma a cinco unidades e destes, 11 estavam 100\% ocupados. Encontramos 11 habitações coletivas com seis a dez unidades habitacionais, estando seis delas inteiramente ocupadas. Ainda, temos sete imóveis com 11 a 15 unidades, onde quatro deles estavam totalmente ocupados. Por fim, foram encontradas cinco habitações coletivas com 16 ou mais unidades, a maior possuindo 19 cômodos, estando três ocupadas em sua totalidade. Ainda sobre a ocupação, das 36 habitações coletivas de aluguel, 13 (36,1\%) abrigam de um a dez moradores; oito (22,2\%) acolhem de 11 a 20 moradores; em quatro $(11,1 \%)$ moram de 31 a 40 inquilinos e, no restante, quatro imóveis $(11,1 \%)$, residem mais de 40 inquilinos.

\section{CONSIDERAÇÕES FINAIS}

Em suma, mesmo com a impossibilidade de se mostrar neste artigo todos os dados coletados, percebe-se como se apresentam precárias, no geral, as condições de habitabilidade das HCPAs inseridas no bairro do Varadouro. Constata-se a má conservação de suas estruturas físicas, a carência de ventilação e iluminação naturais, a precariedade das instalações hidráulicas e elétricas, a coletivização de 
